\title{
Results of a long-term uniform system of neurorehabilitation in patients with incomplete thoracic spinal cord injury
}

\author{
Agnieszka Wincek ${ }^{1, A-F \oplus}$, Juliusz Huber ${ }^{1, A-F}{ }^{\oplus}, K^{2}$ Katarzyna Leszczyńskaa,A,C-F ${ }^{1,}$,

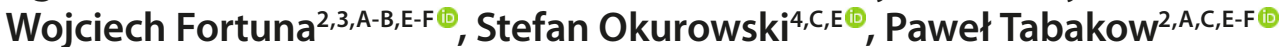 \\ ${ }^{1}$ Department of Pathophysiology of Locomotor Organs, University of Medical Sciences, Poznań, Poland \\ 2 Department of Neurosurgery, Medical University, Wrocław, Poland \\ ${ }^{3}$ Bacteriophage Laboratory, Ludwik Hirszfeld Institute of Immunology and Experimental Therapy, Polish Academy of \\ Sciences, Wrocław, Poland \\ ${ }^{4}$ Neurorehabilitation Centre for Treatment of Spinal Cord Injuries AKSON, Wrocław, Poland \\ A - Research concept and design, B - Collection and/or assembly of data, C - Data analysis and interpretation, \\ $D$ - Writing the article, E-Critical revision of the article, F- Final approval of article
}

Wincek A, Huber J, Leszczyńska K, Fortuna W, Okurowski S, Tabakow P. Results of a long-term uniform system of neurorehabilitation in patients with incomplete thoracic spinal cord injury. Ann Agric Environ Med. 2022; 29(1): 94-102. doi: 10.26444/aaem/135554

\begin{abstract}
Introduction and objective. The results of kinesiotherapy treatment in patients after incomplete spinal cord injury (iSCI) are inconclusive, mostly due to different, subjective evaluation methods. The study aims to evaluate the range of functional regeneration in long-term 13 months follow-up using comparative neurophysiological tests after uniform kinesiotherapy in patients with thoracic iSCl.

Materials and method. Comparative tests were performed of sensory perception in dermatomes Th1-S1, electromyography (at rest-rEMG and during maximal contraction-mcEMG) in the muscles of the trunk and lower extremities, electroneurography (ENG) of the motor fibres of the lower extremities, and motor-evoked potential induced transcranially (MEP) before and after treatment in $25 \mathrm{iSCl}$ patients. All subjects were treated with the same kinesiotherapeutic procedures.

Results. A moderate increase was found in amplitudes in rEMG and mcEMG recordings fromthe rectus abdominis and rectus femoris muscles, MEPs amplitudes, and amplitudes after peroneal nerve stimulations in ENG studies. There was no improvement in sensory perception.

Conclusions. Following the proposed kinesiotherapy algorithm, patients after thoracic iSCl presented a moderate more motor than sensory functions improvement. Applied neurorehabilitation evoked normalization of muscle tension, moderate improvement of rectus abdominis and rectus femoris muscles motor units activity, and motor central and peripheral neural impulses transmission. The comparative neurophysiological assessment provide a more precise and objective insight into the functional status of afferent and efferent systems than the classical clinical approach in iSCl patients.
\end{abstract}

\section{Key words}

rehabilitation, exercise, electromyography, spinal cord injury, neurophysiology, motor evoked potentials

\section{INTRODUCTION}

In Poland, over 200 people suffer from spinal cord injury annually, a number that is even greater worldwide [1]. It concerns more often men up to 40 years of age, and the most common cause is a transport or swimming accident [2]. Incomplete injuries of the thoracic spinal cord (iSCI) most often lead to significant sensory and motor deficits. However, according to the literature data, they may undergo spontaneous functional regeneration and plastic reorganization of the spinal centres [3]. These processes appear more often in injured thoracic rather than in the cervical neuromeres $[4,5]$, due to the anatomical location of the propriospinal neurons at the ceratin levels. They show the projection of crossed and uncrossed axons in the middle and lower thoracic segments, as demonstrated by experimental and clinical studies $[6,7]$. The rudimentary activity of the muscle groups with innervation below the injury characterizes the functional status of patients with

Address for correspondence: Juliusz Huber, Department of Pathophysiology of Locomotor Organs, Poznań University of Medical Sciences, Poznań, Poland E-mail: juliusz.huber@ump.edu.pl

Received: 09.02.2021; accepted: 07.04.2021; first published: 15.04.2021
iSCI at the thoracic level. There can be found slight sensory perception and bladder dysfunction that significantly affect patients' quality of life.

'Rehabilitation treatment is still the primary method of medical care after surgery, decompression of the spinal cord, and stabilization of the spine [8]. Patients should undergo individually adjusted rehabilitation during their inpatient stay and post-hospital rehabilitation. Data on the effectiveness of treatment based mainly on kinesiotherapy are still contradictory due to different and subjective functional evaluation methods of iSCI patients [9]. In most cases, apart from the standard tests included in the ASIA protocol, the basic method is still clinical evaluation consisting of the Ashworth scale, Lovett scale, and highresolution neuroimaging methods [10]. Earlier studies have shown little benefit from conducted conservative therapy, highlighting that the results are influenced by a complex variety of demographical, clinical and environmental factors [11]. Also, in Poland, there is no standardized care programme for patients after iSCI, taking into account all patients' health needs [12].

Clinical, diagnostic neurophysiological metho, such as electromyography (EMG), electroneurography (ENG), and 
somatosensory and motor evoked potentials (SEP and MEP), were previously used more often to diagnose the level of afferent and efferent impulses transmission damage to the spinal cord, than to assess treatment results $[13,14,15,16]$. Moreover, while evoked potential recordings were used to evaluate spinal transmission, EMG and ENG tests were use only occasionally to assess peripheral motor conductivity.

The current guidelines for the conservative treatment of patients with iSCI mainly relate to rehabilitation procedures, including a runway with handrails with support. The main goal is to determine the optimal treatment time to obtain significant improvement in functional motor tests $[8,9]$. The guidelines recommended in 2015 by the American Congress of Rehabilitation Medicine propose the continuous exercise programme dedicated to iSCI patients, which include resistance and aerobic training for not less than 30 minutes twice a week. Stretching and a range of motion exercises and those for maintaining the vertical body position should be applied for 5-15 minutes daily [17].

\section{OBJECTIVE}

The study aims to evaluate the functional regeneration of the spinal cord assessed with comparative neurophysiological tests. The assessment was performed before and after a cycle of intensive, individually adjusted neurorehabilitation used as the only treatment in all presented cases. The paper describes a proposal for an original conservative treatment algorithm and assesses its effectiveness in a long-term follow-up, 13 months on average.

\section{MATERIALS AND METHOD}

Patients and clinical evaluation. The study group consisted of 25 patients (women $\mathrm{N}=7$, men $\mathrm{N}=18$ ) with incomplete thoracic spinal cord injury. Their ages from 21-72 years, with an average height of $175 \mathrm{~cm}$, and degree of spinal injury assessed in the ASIA scale as B-D (Tab. 1).

Table 1. Demographic data and health status of patients

\begin{tabular}{lcc}
\hline Variable & Mean \pm SD & Min-Max \\
\hline Age & $37.8 \pm 11.11$ & $21-72$ \\
\hline Height $(\mathrm{cm})$ & $175.6 \pm 8.64$ & $156-194$ \\
\hline Spinal injury levels & Th4,5,6; & Th3- \\
\hline Time from spine injury (months) & Th11,12 & Th12 \\
\hline Observation time before-after treatment (months) & $7.7 \pm 2.0$ & $4-12$ \\
\hline ASIA status & $13.6 \pm 7.9$ & $6-34$ \\
\hline
\end{tabular}

Magnetic resonance imaging (MRI) evaluated the severity of the thoracic spinal cord injury and determined its neuromer level. The primary criterion for including patients in the study group was the preservation of at least $1 / 3$ of the spinal cord structures at the thoracic Th3-Th12 levels, and time from damage of from four months to a year. All subjects had to be referred for a neurophysiological examination by a neurologist who confirmed the absence of contraindications. Exclusion criteria were the lack of consent to conduct a neurophysiological examination, presence of a pacemaker, cochlear implant, epilepsy, mental disability, pregnancy, psychotropic drugs intake, neurological disorders, such as stroke, or the consequences of severe craniocerebral injuries.

Patients underwent conservative neurorehabilitation treatment after performing surgical stabilization procedures on the spine from the posterior approach. The neurosurgical operations in these patients consisted primarily of decompression of the spinal cord from fractured bone fragments, securing a ruptured vessel, ensuring proper venous and arterial flow, and removing bleeding consequences. A multi-level stabilization of the spine with the use of transpedicular screws was used. The time from the onset of spinal cord injury to surgical treatment ranged from several hours to several days after the injury. Analysis of patients' medical history revealed coexisting comorbidities, e.g. arterial hypertension (5/25), diabetes (1/25), COPD (1/25) or ischemic heart disease $(1 / 25)$.

Before treatment, the following pathological symptoms were found in the clinical studies: spasticity $(3 / 25)$, pressure ulcers (1/25), depression (5/25), bowel and urinary dysfunction (20/25), and chronic pain (4/25). Pharmacological treatment included the application of antidepressants $(5 / 25)$, baclofen (3/25), analgesics (4/25) and insulin (1/25). The therapy took place in the rehabilitation centre (Akson Neurorehabilitation Center in Wrocław, Poland) and lasted seven months, on average, after the injury.

The personalized intensity of physiotherapeutic treatment for iSCI patients has been designed based on neurophysiological tests, and aimed to support the restoration of motor and sensory function using the concept of neuroplasticity in the nervous system [4]. All patients assessed their functional status before and after the particular steps of therapy a neurologist and neurosurgeon with the assistance of a physiotherapist, using tools including the ASIA scale and Walking index.

Rehabilitation treatment. Neurorehabilitation (Fig. 1A-G) included motor skills training assisted by a physiotherapist, aimed at improving muscles motor units contraction (minimum three hours a day), training of balance and body stabilizatio, and using a mobile platform (one hour a day). The patient was positioned to standing using a verticalization bed. Active and passive exercises were also introduced to increase the range of motion in the spine and joints of the lower extremities. Gait training (at least once a day, three hours a week within a range from 30-150 meters, or more) was carried out. The distance progression milestones during gait re-education on a runway with handrails as support were determined in the Walking Index. At the same time, a decrease of muscle tension was performed at rest by relaxation procedures in the muscles of the trunk and lower extremities. Kinesiotherapy techniques were then introduced, aimed at reducing pathological spinal reflexes (one hour a day). Sensory stimulation (one hour a day) was performed to compensate for the deficits of perception. The kinesiotherapy programme also included postural therapy and exercises to improve muscles and fascia's flexibility, passive, active, and assisted exercises, and training of the partially paralyzed muscle groups with a load (minimum 100 grams). Massage was also used to prevent trophic changes, especially bedsores in areas of the body below the level of the spinal cord injury. Breathing exercises and functional rehabilitation, including independence in a wheelchair, and systematic aseptic cleaning of the bladder were taught. 

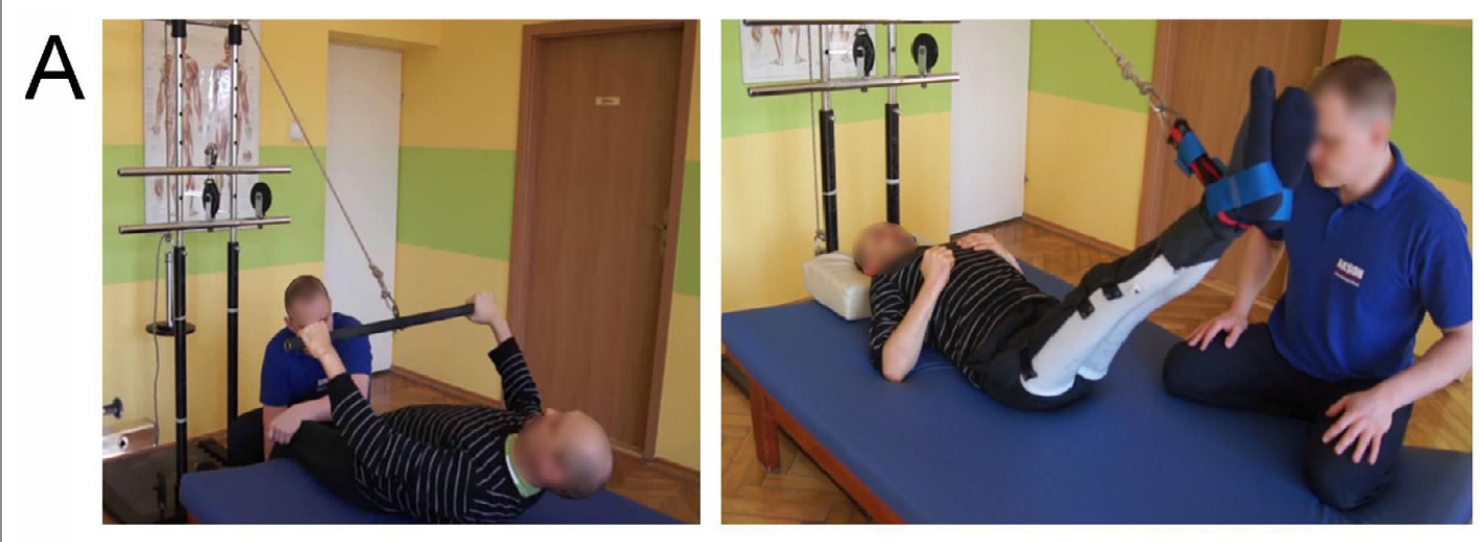

$\mathrm{B}$
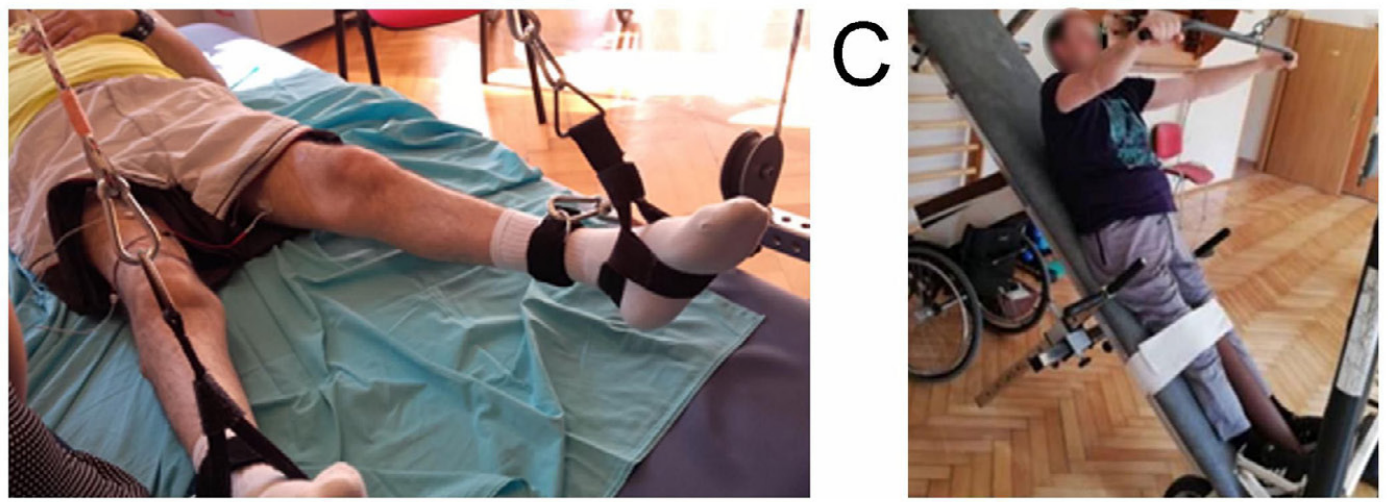

$\mathrm{D}$

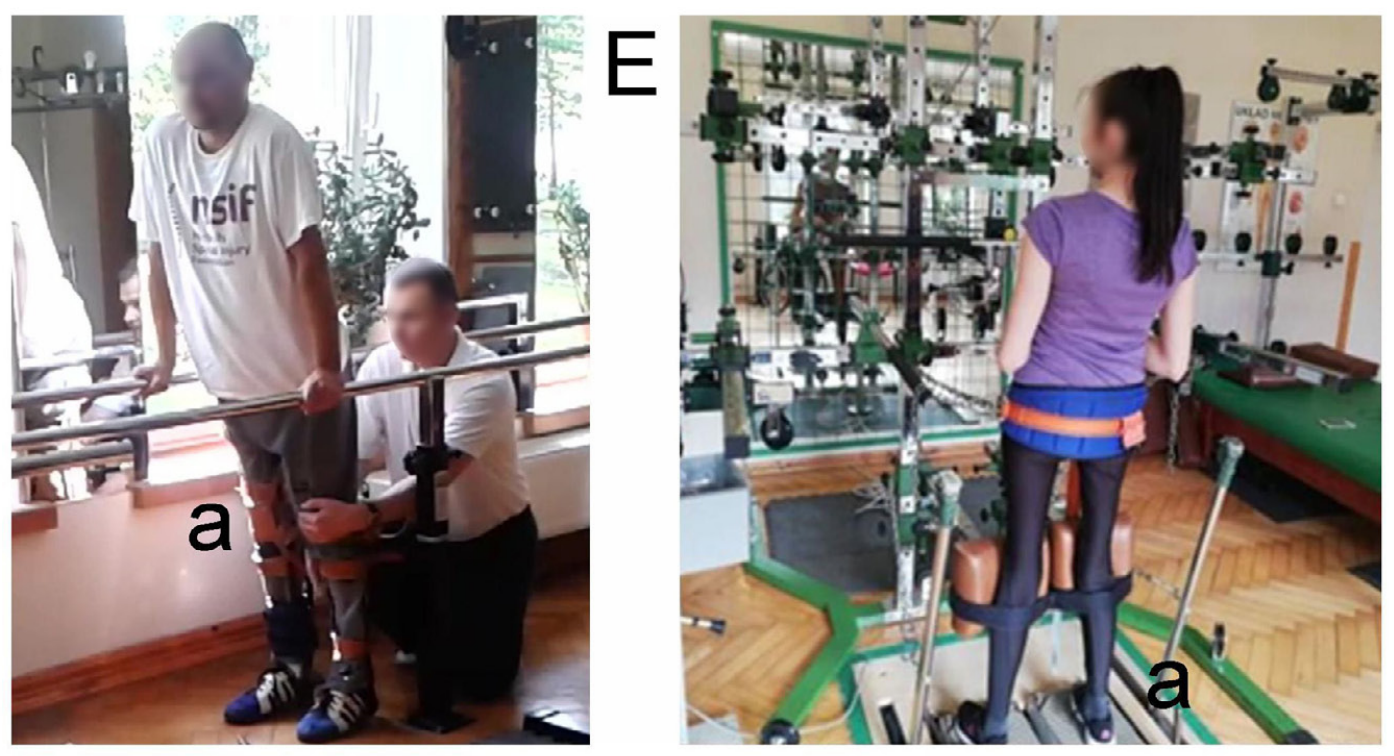

$\mathrm{F}$

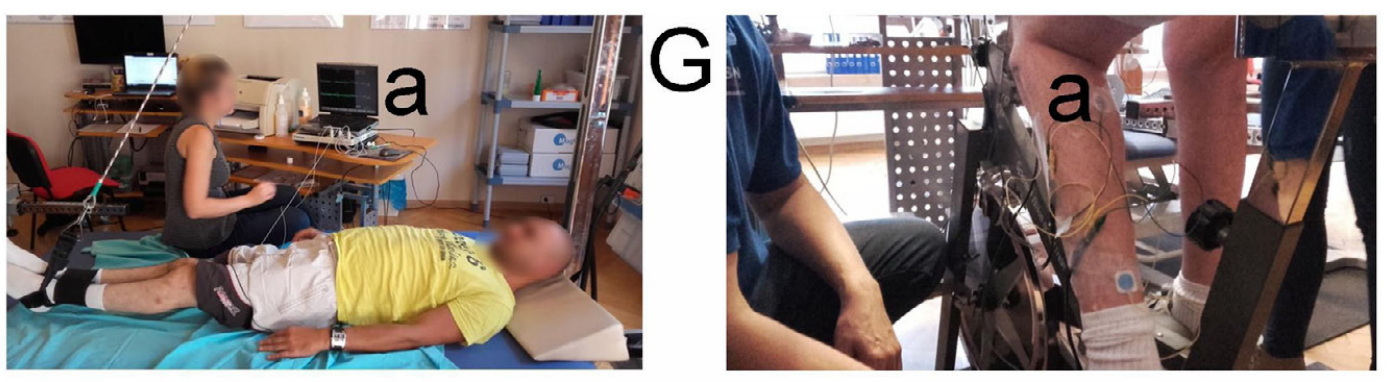

Figure 1. Photographs illustrate the principles of rehabilitation and diagnostic protocol applied to iSCl patients.

A, B - range of motion and stretching exercises; C- verticalization; D- training of locomotion on a runway with handrails for support (a); E - posture and balance exercises on a vibration platform (a); F - bilateral recordings of sEMG from upper, abdominal and lower extremities muscles; $G$ - $s E M G$ recordings during exercises on a stationary bicycle. 
All patients underwent rehabilitation during the day at a time convenient for the patient, about five hours a day, five times a week. This study included patients with no additional physical therapy applied, such as electro- or magneto[stimulation. The patients received individual treatment adjusted for their health status and orthopaedic supplies, such as ortheses, if necessary.

Another element of the rehabilitation programme was rotor and cyclo-ergometer training using a central pattern generator gait mechanism (Fig. 1 G). During these exercises, the methodology took into consideration the locomotor cycle, speed of rotation, time and number of intervals, the nature and size of the load that could be adjusted on the rotor. Patients were instructed to watch EMG recordings displayed on the recorder's screen; thus, a motivational effect was obtained when the increase of the amplitude was subsequently observed.

Neurophysiological assessment. Sensory perception regarding dermatomal innervation was investigated using von Frey's filaments (Semmes-Weinstein monofilament test). Abnormalities in skin receptors threshold of perception were determined using flexible silicone filaments with a diameter of $0.55 \mathrm{~mm}$ for hypoaesthesia detection. The normal perception was diagnosed when touching with a filament of $0.3 \mathrm{~mm}$ diameter evoked proper excitation. Index 1- a normal perception, or 0- hypoaesthesia was applied [18].
Neurophysiological recordings (EMG, ENG and MEP) were performed with the Keypoint four-channel diagnostic system (Medtronic, Skovlunde, Denmark); the motor potentials were induced with a single magnetic stimulus triggered from a MagPro generator (Medtronic A / S, Skovlunde, Denmark).

The activity of muscle motor units with the bipolar, surface electrodes was studied during global electromyography (sEMG) recordings. Standard disposable $\mathrm{Ag} / \mathrm{AgCl}$ surface electrodes with an active surface of $5 \mathrm{~mm}^{2}$ were used. The ground electrode was located on the distal part of the leg. Tests were performed under conditions of bilateral relaxation (rEMG) and maximal contractions (mcEMG) from the rectus abdominis muscles (normal amplitude $>400 \mu \mathrm{V}$ ), rectus femoris muscles (normal amplitude $>600 \mu \mathrm{V}$ ), tibialis anterior muscles (normal amplitude $>700 \mu \mathrm{V}$ ), and extensor digitorum longus muscles (normal amplitude $>800 \mu \mathrm{V}$ (Fig. 2A, Fig. 3a). The principles of the methodology have been described elsewhere $[19,20,21$, 22]. Generally, the upper $10 \mathrm{kHz}$ and lower $20 \mathrm{~Hz}$ filters of the recorder are used. In the first stage of the trial, the patient was asked to fully relax the examined muscles and then perform a maximal contraction for five seconds, while the simultaneous recording took place. The test was conducted three times, the recording with the highest amplitude (in $\mu \mathrm{V}$ ) and frequency (in $\mathrm{Hz}$ ) parameters was selected for analysis. EMG recordings were made at the time base $80 \mathrm{~ms} / \mathrm{D}$, amplification $20-1000 \mu \mathrm{V}$. The amplitude at no more than $20-25 \mu \mathrm{V}$ in $\mathrm{rEMG}$ recording reflected the proper muscle tension [23].

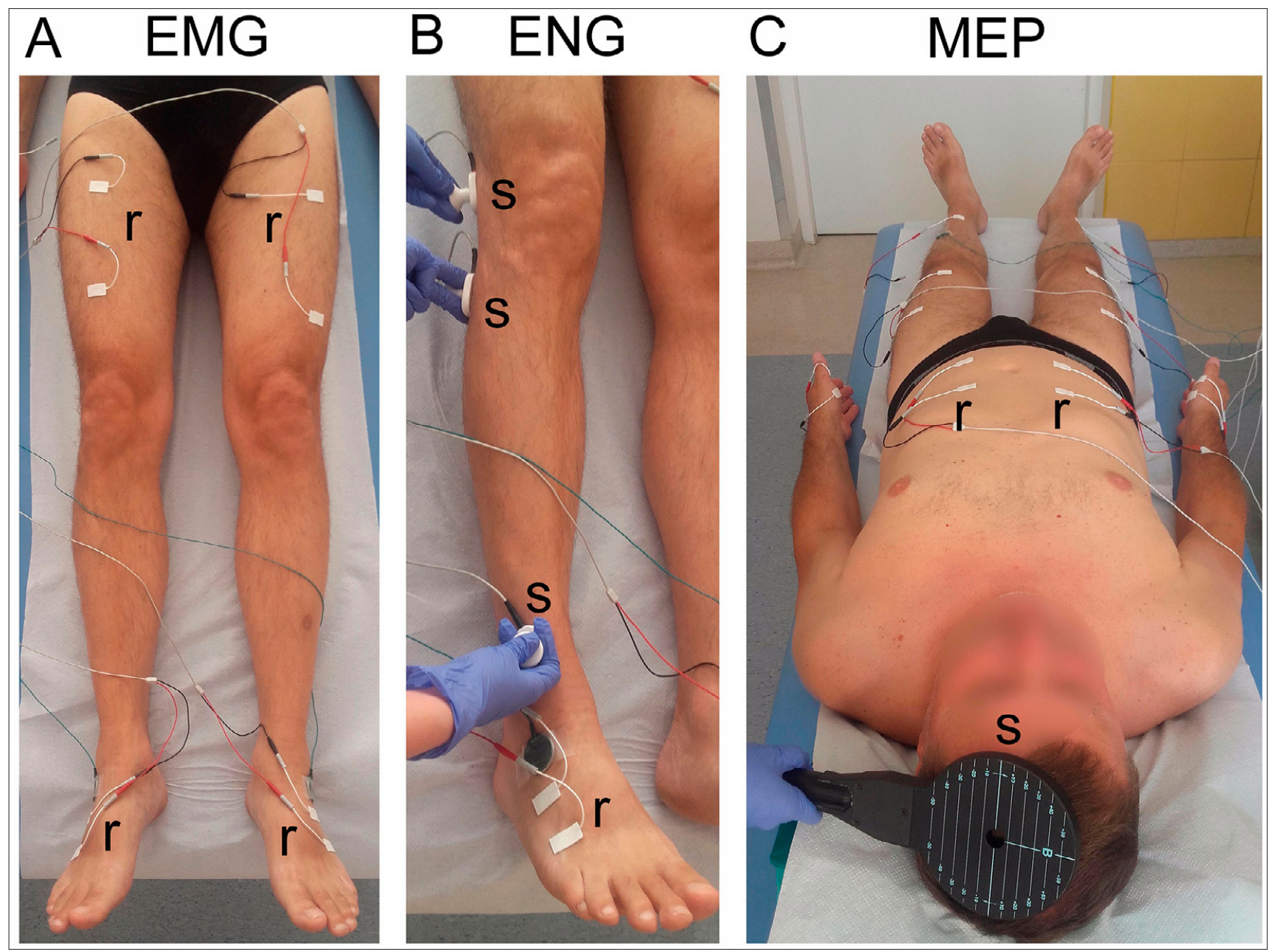

Figure 2. Photographs illustrating principles of neurophysiological recordings in electromyographic (A, EMG), electroneurographic (B, ENG) and motor evoked potentials (C, MEP) studies; $r$ - recording, s - stimulation 
The transmission of nerve impulses in the peroneal and tibial nerve motor fibres, both peripherally and at the level of the L5 and S1 ventral roots, was examined bilaterally using ENG (M- and F-waves respectively (Fig. 2B, Fig. 3b). Recordings of compond muscles action potentials (CMAP, $M$-wave) were made with surface electrodes from the extensor digitorum longus muscles (Fig. 2B, 'r') and abductor hallucis longus muscles following stimulation with electrical stimuli (rectangular $0.2 \mathrm{~ms}$ duration at $1 \mathrm{~Hz}$, intensity $1-80 \mathrm{~mA}$ ) applied on the anatomical course of the nerves at the ankle and popliteal area (Fig. 2B, 's'). The parameters of amplitude (in $\mu \mathrm{V}$ ) and latency (in $\mathrm{ms}$ ) were analyzed in the M-wave ENG recordings. Additionally recorded and analyzed were the long-latency F-waves evoked potentials following stimulation of the peroneal nerves, together with their frequencies, during 20 positive $\mathrm{M}$-waves recordings (Fig. 3b). F-waves were recorded to ascertain the pathology in transmission within L5-S1 ventral roots. ENG recordings were collected at the amplification of $100-5,000(\mu \mathrm{V})$ and a time base of $8 \mathrm{~ms}$ [24].

The motor evoked potentials (MEP) study evaluated the efferent transmission in the spinal pathways. MEP potentials were induced by generating a transcranial magnetic stimulus through the $\mathrm{C} 100$ coil with a strength of $80 \%$ of the maximum intensity at 2.4T (Fig. 2C, 's'). Single sinusoidal stimuli with a duration of $5 \mathrm{~ms}$ over the primary motor cortex (M1) area were applied, aimed at the transcranially-stimulating axons that originate from the corticospinal tract cells. Motor representation areas that innervate the trunk and the muscles of lower extremities were excited. Such stimulation delivered from a C100 coil may also penetrate structures lying $3-5 \mathrm{~cm}$ below the skull's surface with the activation of the cells of origin of rubrospinal pathways [25]. A tracking stimulus at $40 \%$ of the maximum output was used to find the 'hot spot' [26]. The analyzed parameters of the MEP test were amplitude (in $\mu \mathrm{V}$ ) and latency (in $\mathrm{ms}$ ). The proportional decrease in the amplitude parameter concerning the expected value was interpreted as a decrease in the number of active axons in the spinal cord's white matter efferent pathways. The increase in the latency parameter value indicated the phenomenon of the impulse slowing down within the efferent pathway.

The same set of neurophysiological studies was applied to 42 healthy volunteers to obtain reference values (Fig. 3A a-c). The control group's age range was $35.7 \pm 5.2$ years $(26-45)$, and their height $-163-179 \mathrm{~cm}$, mean $-173.3 \pm 5.9 \mathrm{~cm}$. The anthropometric properties of the healthy volunteers did not differ from the study group.

Before starting the study, the patients provided written consent to participate in the two neurophysiological tests before and after the application of neurorehabilitation. The research was carried out following the Helsinki Declaration and permission granted by the Local Bioethics Committee (559/2018).

Statistical analyses. Statistical analyses were performed using Statistica software version 13.1 (StatSoft, Poland). Descriptive statistics were reported as mean, standard deviations (SD), median, minimal and maximal values (range). Normality distribution was assessed using the Shapiro-Wilk test. Because the data were not normally distributed, the non-parametric Wilcoxon signed-ranks test was used to compare dependent variables. $\mathrm{P} \leq 0.05$ was considered as statistically significant.

Before completion of the study, preliminary statistical analysis determined the required sample size using the primary outcome variable EMG recordings from rectus femoris muscles before and after treatment with a power of $80 \%$, and a significance level of 0.05 (two-tailed). The mean and standard deviation (SD) was calculated using the data from the first ten subjects. The sample size software estimated that 25 patients would be needed.

\section{RESULTS}

The applied treatment did not bring improvement in sensory perception within the upper thoracic, lower thoracic upper lumbar, and lumbosacral dermatomes. Moreover, the frequency of positive results worsened significantly at the L3-S1 levels on the right side at $\mathrm{p}=0.033$ (Tab. 2).

Table 2. Results of sensory perception studies performed in a group of patients before and after treatment evaluated in thoracic and lumbosacral dermatomes bilaterally with von Frey's filaments. The mean value expresses the frequency of positive excitations of skin receptors

\begin{tabular}{lcccccc}
\hline \multirow{2}{*}{ Dermatomes } & \multirow{2}{*}{ Side } & \multicolumn{3}{c}{ Before } & \multicolumn{3}{c}{ After } & \multirow{2}{*}{ p-value } \\
\cline { 2 - 7 } Th $_{1}-\mathrm{Th}_{8}$ (8 levels) & & mean $\pm S D$ & min-max & mean $\pm S D$ & min-max & \\
\cline { 2 - 7 } & left & $7.6 \pm 1.1$ & $4-8$ & $7.3 \pm 1.2$ & $5-8$ & 0.201 \\
\hline \multirow{2}{*}{$\mathrm{Th}_{9}-\mathrm{L}_{2}$ (6 levels) } & right & $3.8 \pm 2.4$ & $0-6$ & $3.0 \pm 2.6$ & $0-6$ & 0.051 \\
\cline { 2 - 7 } & left & $3.7 \pm 2.5$ & $0-6$ & $3.2 \pm 2.5$ & $0-6$ & 0.208 \\
\hline \multirow{2}{*}{$\mathrm{L}_{3}-\mathrm{S}_{1}$ (4 levels) } & right & $1.4 \pm 1.9$ & $0-4$ & $0.8 \pm 1.4$ & $0-4$ & $0.033^{*}$ \\
\cline { 2 - 7 } & left & $1.5 \pm 1.9$ & $0-4$ & $1.0 \pm 1.6$ & $0-4$ & 0.063 \\
\hline
\end{tabular}

${ }^{*} \mathrm{p} \leq 0.05$

Only a few patients showed increased muscle tension as assessed from amplitude parameter values in $\mathrm{rEMG}$ recordings. The mean values of amplitudes before treatment at about $10 \mu \mathrm{V}$ indicated hypotonia phenomenon instead of spasticity. The same parameter reached about $15 \mu \mathrm{V}$ after treatment, which is characteristic for normal muscle tension, especially in the rectus femoris more than the extensor digitorum longus muscles at $\mathrm{p}=0.034-0.026$ (Tab. 3, left side; Fig. 3B,C a).

Abnormalities in muscle motor unit activity recorded during maximal contraction in mcEMG studies were found in more distal than proximal muscle groups, bilaterally. The improvement following the applied treatment, although detectable, was statistically significant only in the extensor digitorum longus muscle (Tab. 3, right side; Fig. 3B,C a).

Most patients did not present abnormalities in the transmission of nerve impulses within motor fibres of tibial nerves, peripherally.This was observed in the parameters of M-wave potentials recordings in ENG studies (Tab.4, lower part), where both amplitudes and latencies were norma, compared to the reference values studied in the healthy volunteers. The frequencies of F-wave recordings after tibial nerve stimulation indicated the proper efferent transmission of nerve impulses in the $\mathrm{S} 1$ ventral roots, bilaterally. No significant changes were found in the parameters mentioned above that were recorded in pre-and post-treatment observations. On the other hand, as concluded from the electroneurographic recordings of $\mathrm{M}$-waves following electrical stimulation of peroneal nerves peripherally, degenerative changes in axons were indicated by the occurrence of diminishing amplitude parameters (Fig. 3B, Cb). The applied treatment led to significant improvement at $\mathrm{p}=0.04$, suggesting a regenerative 


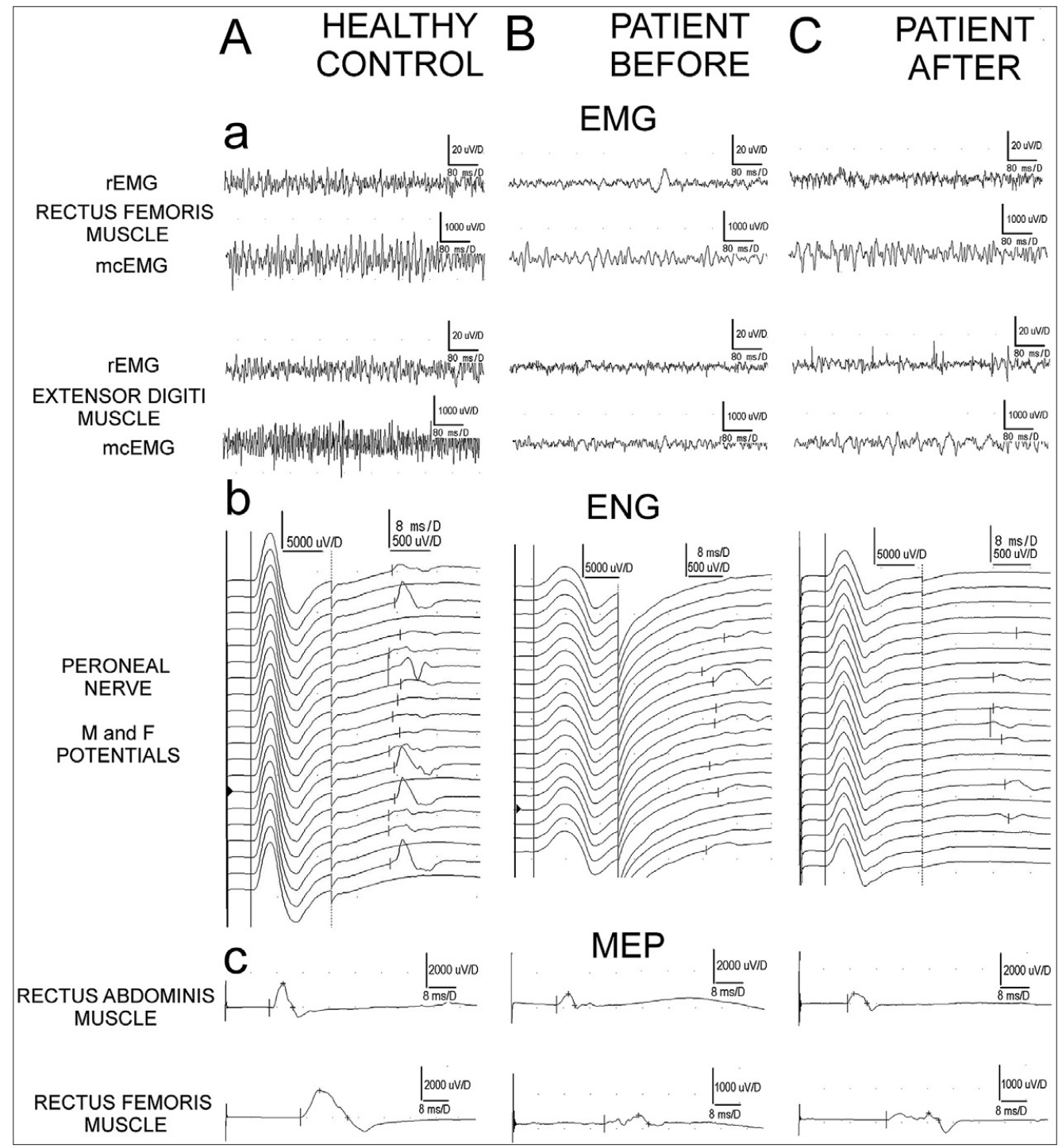

Figure 3. Examples of EMG (a), ENG (b) and MEP (c) recordings in a healthy subject (A) and a patient with iSCI before (B) and after (C) treatment for comparison. Note different amplifications in MEPs recorded in a patient vs control.

rEMG - electromyography recorded at rest, mcEMG - electromyography during maximal contraction lasting 5 seconds

Table 3. Summary of results from EMG amplitude recordings $(\mu \mathrm{V})$ in patients before and after treatment

\begin{tabular}{|c|c|c|c|c|c|c|c|c|c|}
\hline \multirow{2}{*}{$\begin{array}{l}\text { EMG at rest } \\
\text { Recordings site }\end{array}$} & \multirow[b]{2}{*}{ Side } & Before & After & \multirow[b]{2}{*}{$p$-value } & \multirow{2}{*}{$\begin{array}{l}\text { EMG during maximal contraction } \\
\text { Recording site }\end{array}$} & \multirow[b]{2}{*}{ Side } & Before & After & \multirow[b]{2}{*}{$p$-value } \\
\hline & & $\begin{array}{l}\min -\max \\
\operatorname{mean} \pm S D\end{array}$ & $\begin{array}{l}\min -\max \\
\operatorname{mean} \pm S D\end{array}$ & & & & $\begin{array}{l}\min -\max \\
\operatorname{mean} \pm S D\end{array}$ & $\begin{array}{l}\min -\max \\
\operatorname{mean} \pm S D\end{array}$ & \\
\hline \multirow{2}{*}{$\begin{array}{l}\text { rectus abdominis } \\
\text { muscle }\end{array}$} & right & $\begin{array}{c}5-20 \\
9.8 \pm 3.9\end{array}$ & $\begin{array}{c}5-40 \\
14.0 \pm 7.5\end{array}$ & $0.010^{*}$ & \multirow{2}{*}{$\begin{array}{l}\text { rectus abdominis } \\
\text { muscle }\end{array}$} & right & $\begin{array}{c}0-2000 \\
506.0 \pm 538.8\end{array}$ & $\begin{array}{c}0-2000 \\
618.0 \pm 622.0\end{array}$ & 0.520 \\
\hline & left & $\begin{array}{c}5-25 \\
10.4 \pm 5.0 \\
\end{array}$ & $\begin{array}{c}5-30 \\
13.4 \pm 6.2 \\
\end{array}$ & $0.046^{*}$ & & left & $\begin{array}{c}0-2200 \\
467.0 \pm 522.0\end{array}$ & $\begin{array}{c}0-2400 \\
630.0 \pm 671.9\end{array}$ & 0.298 \\
\hline $\begin{array}{l}\text { rectus femoris } \\
\text { muscle }\end{array}$ & left & $\begin{array}{c}5-20 \\
10.6 \pm 4.9\end{array}$ & $\begin{array}{c}5-50 \\
14.0 \pm 9.1\end{array}$ & $0.026^{*}$ & $\begin{array}{l}\text { rectus femoris } \\
\text { muscle }\end{array}$ & left & $\begin{array}{c}0-4000 \\
350.6 \pm 882.4\end{array}$ & $\begin{array}{c}0-4000 \\
443.0 \pm 970.7\end{array}$ & 0.184 \\
\hline \multirow{2}{*}{$\begin{array}{l}\text { tibialis anterior } \\
\text { muscle }\end{array}$} & right & $\begin{array}{c}5-20 \\
10.2 \pm 4.2 \\
\end{array}$ & $\begin{array}{c}5-25 \\
14.4 \pm 6.2 \\
\end{array}$ & $0.004^{*}$ & \multirow{2}{*}{$\begin{array}{l}\text { tibialis anterior } \\
\text { muscle }\end{array}$} & right & $\begin{array}{c}0-100 \\
34.2 \pm 35.5\end{array}$ & $\begin{array}{c}0-300 \\
55.6 \pm 80.6 \\
\end{array}$ & 0.394 \\
\hline & left & $\begin{array}{c}5-30 \\
10.4 \pm 5.6\end{array}$ & $\begin{array}{c}5-20 \\
14.2 \pm 5.5\end{array}$ & $0.011^{*}$ & & left & $\begin{array}{c}0-150 \\
30.4 \pm 39.4\end{array}$ & $\begin{array}{c}0-200 \\
42.6 \pm 59.4\end{array}$ & 0.629 \\
\hline $\begin{array}{l}\text { extensor digitorum longus } \\
\text { muscle }\end{array}$ & left & $\begin{array}{c}5-20 \\
10.6 \pm 4.6\end{array}$ & $\begin{array}{c}5-25 \\
14.4 \pm 6.8\end{array}$ & $0.034^{*}$ & $\begin{array}{l}\text { extensor digitorum longus } \\
\text { muscle }\end{array}$ & left & $\begin{array}{c}0-200 \\
32.4 \pm 50.8\end{array}$ & $\begin{array}{c}0-600 \\
63.2 \pm 129.7\end{array}$ & 0.345 \\
\hline
\end{tabular}


process in left peroneal motor fibres (Tab. 4, upper part). Abnormalities in the L5 ventral roots' transmission remained unchanged, as assumed from low-frequency recordings of F-waves (Fig. 3B,C b).

Motor-evoked potentials recordings following bilateral transcranial magnetic stimulation verified changes in efferent transmission within spinal tracts of axonal type, based on recordings of the low-amplitude parameters, constituting in general $1 / 3-1 / 4$ of reference values (Tab. 5). This was recorded ore in the trunk and hip than calf muscle, where MEPs' amplitudes were recorded rudimentary (Fig. 3B, Cc). The treatment provided significant improvement of amplitude parameter in recordings from both rectus femoris muscles at $\mathrm{p}=0.05$.

Table 4. Results of ENG recordings in patients before and after treatment

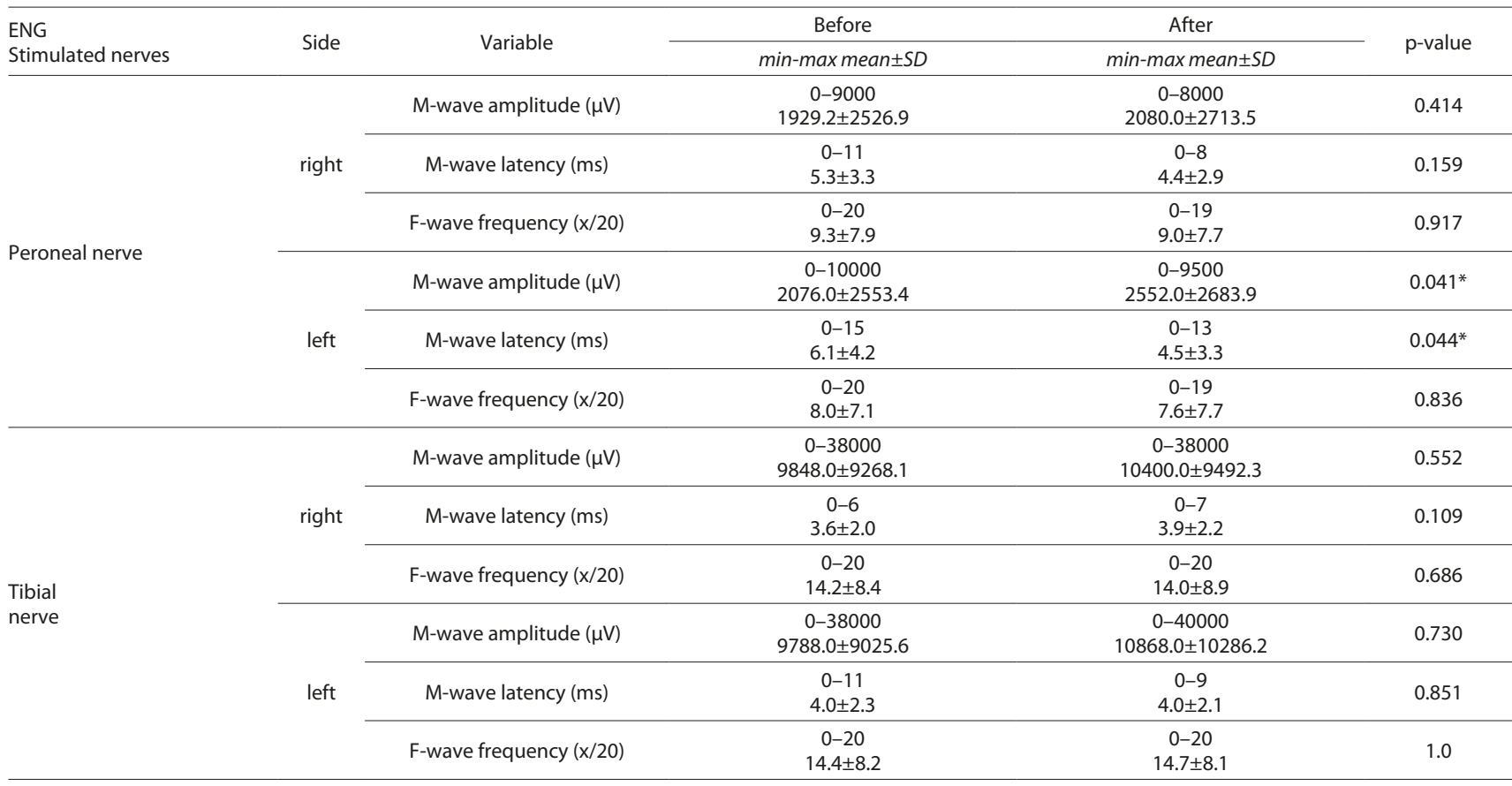

${ }^{*} \mathrm{p} \leq 0.0$

Table 5. Results of MEPs recordings in patients before and after treatment

\begin{tabular}{|c|c|c|c|c|c|}
\hline \multirow{2}{*}{$\begin{array}{l}\text { MEP } \\
\text { Recording site }\end{array}$} & \multirow{2}{*}{ Side } & \multirow{2}{*}{ Variable } & Before & after & \multirow{2}{*}{$\mathrm{p}$-value } \\
\hline & & & min-max mean $\pm S D$ & min-max mean $\pm S D$ & \\
\hline \multirow{4}{*}{$\begin{array}{l}\text { rectus abdominis } \\
\text { muscle }\end{array}$} & \multirow{2}{*}{ Right } & Amplitude $(\mu \mathrm{V})$ & $\begin{array}{c}40-1100 \\
353.2 \pm 370.3\end{array}$ & $\begin{array}{c}50-1500 \\
392.0 \pm 424.7\end{array}$ & 0.625 \\
\hline & & Latency (ms) & $\begin{array}{c}9-20 \\
14.1 \pm 2.6\end{array}$ & $\begin{array}{c}10-20 \\
14.2 \pm 2.1\end{array}$ & 0.751 \\
\hline & \multirow{2}{*}{ Left } & Amplitude $(\mu \mathrm{V})$ & $\begin{array}{c}30-1100 \\
345.2 \pm 369.3\end{array}$ & $\begin{array}{c}50-1500 \\
384.0 \pm 418.0\end{array}$ & 0.943 \\
\hline & & Latency (ms) & $\begin{array}{c}10-19 \\
14.3 \pm 2.4\end{array}$ & $\begin{array}{c}10-22 \\
14.3 \pm 2.4\end{array}$ & 0.954 \\
\hline \multirow{4}{*}{$\begin{array}{l}\text { rectus femoris } \\
\text { muscle }\end{array}$} & \multirow{2}{*}{ Right } & Amplitude $(\mu \mathrm{V})$ & $\begin{array}{c}0-2500 \\
221.0 \pm 571.1 \\
\end{array}$ & $\begin{array}{c}0-7000 \\
520.0 \pm 1494.4\end{array}$ & $0.05^{*}$ \\
\hline & & Latency (ms) & $\begin{array}{c}0-63 \\
13.1 \pm 18.0\end{array}$ & $\begin{array}{c}0-37 \\
8.2 \pm 12.4 \\
\end{array}$ & 0.480 \\
\hline & \multirow{2}{*}{ Left } & Amplitude $(\mu \mathrm{V})$ & $\begin{array}{c}0-6000 \\
503.6 \pm 1420.6\end{array}$ & $\begin{array}{c}0-10000 \\
1060.0 \pm 2700.4\end{array}$ & $0.05^{*}$ \\
\hline & & Latency (ms) & $\begin{array}{c}0-73 \\
16.4 \pm 22.6\end{array}$ & $\begin{array}{c}0-62 \\
13,4 \pm 17,9\end{array}$ & 0.754 \\
\hline \multirow{4}{*}{$\begin{array}{l}\text { tibialis anterior } \\
\text { muscle }\end{array}$} & \multirow{2}{*}{ Right } & Amplitude $(\mu \mathrm{V})$ & $\begin{array}{c}0-1000 \\
44.0 \pm 199.6 \\
\end{array}$ & $\begin{array}{c}0-200 \\
20.6 \pm 46.2 \\
\end{array}$ & 0.327 \\
\hline & & Latency (ms) & $\begin{array}{c}0-41 \\
3.6 \pm 10.7 \\
\end{array}$ & $\begin{array}{c}0-50 \\
8.6 \pm 16.5\end{array}$ & 0.161 \\
\hline & \multirow{2}{*}{ Left } & Amplitude $(\mu \mathrm{V})$ & $\begin{array}{c}0-1000 \\
48.0 \pm 199.7 \\
\end{array}$ & $\begin{array}{c}0-50 \\
12.0 \pm 21.8 \\
\end{array}$ & 0.917 \\
\hline & & Latency (ms) & $\begin{array}{c}0-36 \\
4.5 \pm 11.1\end{array}$ & $\begin{array}{c}0-44 \\
7.5 \pm 13.9\end{array}$ & 0.401 \\
\hline
\end{tabular}




\section{DISCUSSION}

The obtained results may provide evidence for the moderate effectiveness of the proposed, applied algorithm of neurorehabilitation evaluated with the comparative, objective neurophysiological tests. They show a functional improvement in the transmission of neural impulses more in the efferent spinal tracts than in the afferent pathways. Similar results have been rarely reported in previous studies where the plasticity of locomotor and sensory interactions was shown, especially in patients with spinal injuries at thoracic levels $[4,27,28]$. The uncrossed and crossed axons of the propriospinal neurons at the lower thoracic levels are considered important structures in transmitting efferent impulses from supraspinal levels in iSCI patients. Thus, they may be responsible for the functional recovery detected in the current and previous studies $[6,7]$. With the highest incidence of Th4-6 and Th11-12 iSCI patients, the current results confirm that this part of the spinal cord is especially susceptible to the improvement of sensorimotor deficits. This improvement, however, became apparent in functional, precise neurophysiological studies. The scales of the clinical evaluation used so far in the assessment of iSCI patients' functional state were related to the observation of their locomotor advances.Thus, they could have been burdened with the subjectivity of both the examiner and the patient [8].

The proposed methods of clinical neurophysiology include certain methodological canons. They are repeatable according to the same criteria and principles used in different laboratories; the parameters are measurable in milliseconds and microvolts; therefore, they are characterized by objectivity and a higher confidence in the result obtained. Similar neurophysiological assessments of iSCI patients' health status have not often been utilized [26] because they are not always available in treatment centres or considered as evaluation tools.

One of the factors influencing the effectiveness of the introduced treatment might have been the spinal injury time. According to Sandrow-Feinberg and Houlé, the onset of optimal rehabilitation to evoke the most positive functional effects after iSCI seems to be 3-6 months [29]. In the current study, the patients had up to 13 months of supervised kinesiotherapy which, on average, was introduced six months after iSC. The symptoms of spinal oedema and neuroinflammation retreated, and formation of the glial scar completed; therefore, the signs of spontaneous regeneration following the applied personalized kinesiotherapy became more apparent. It can be assumed that the positive effects of the treatment were achieved not only due to the personalization of the proposed rehabilitation algorithm adapted to the patient's capabilitie, but also through the physiotherapist's direct supervision and motivation during the entire treatment period with all performed exercises. The study by Taylor-Schroeder et al. provided evidence of similar results [30]; however, in the current study, no descriptions were found of a kinesiotherapy algorithm, as proposed in this study. Burns et al. and Effing et al. presented convincing evidence for improved muscle strength, together with the effectiveness of joints range of motion exercises supplemented by walking training with parallel bars in iSCI patients $[9,31]$.

The limitations of the presented study are the heterogeneity and low number of examined patients, caused by the strict requirements of similar anatomopathological properties of injured spinal structures evaluated preliminary in MRI studies. There could also be slight, unavoidable differences in the number and repeatability of applied kinesiotherapy procedures to all the examined group members, which may influence the diversity of the results [32].

\section{CONCLUSIONS}

Following the kinesiotherapy's proposed algorithm as the only conservative treatment method in the presented iSCI cases, patients after incomplete thoracic spinal cord injuries showed moderate motor improvement rather than sensory functions. Applied treatment evokes normalization of muscle tension, moderate improvement of rectus abdominis and rectus femoris muscles motor units activity, and transmission of motor central and peripheral neural impulses. Comparative neurophysiological assessment of patients after incomplete thoracic spinal cord injuries provides more precise insight into the functional status of the afferent and efferent systems than classical clinical approach, both before and after applied conservative treatment.

\section{REFERENCES}

1. Tederko P, Krasuski M, Ptyushkin P, Selb M, Pawlak K, Skrzypczyk $\mathrm{R}$, et al. Need for a comprehensive epidemiologic study of spinal cord injury in Poland: findings from a systematic review. Spinal Cord. 2013;51:802-808

2. Fehlings MG, Tetreault LA, Wilson JR, Kwon BK, Burns AS, Martin AR, et al. A Clinical Practice Guideline for the Management of Acute Spinal Cord Injury: Introduction, Rationale, and Scope. Global Spine J. 2017;7(3S):84S-94S.

3. Curt A, Schwab ME, Dietz V. Providing the clinical basis for new interventional therapies: refined diagnosis and assessment of recovery after spinal cord injury. Spinal Cord. 2004;42(1):1-6.

4. Flynn JR, Graham BA, Galea MP, Callister RJ. The role of propriospinal interneurons in recovery from spinal cord injury. Neuropharmacol. 2011;60:809-822.

5. Nas K, Yazmalar L, Şah V, Aydın A, Öneş K. Rehabilitation of spinal cord injuries. World J Orthop. 2015;18:6(1):8-16.

6. Azim E, Jiang J, Alstermark B, Jessell TM. Skilled reaching relies on a V2a propriospinal internal copy circuit. Nature. 2014;508(7496):357363.

7. Rasmussen R, Carlsen EM. Spontaneous functional recovery from incomplete spinal cord injury. J Neurosci. 2016;36(33):8535-8537.

8. Fehlings MG, Tetreault LA, Aarabi B, Anderson P, Arnold PM, Brodke DS, et al. A Clinical Practice Guideline for the Management of Patients With Acute Spinal Cord Injury: Recommendations on the Type and Timing of Rehabilitation. Global Spine J. 2017;7(3S):231S-238S.

9. Burns AS, Marino RJ, Kalsi-Ryan S, Middleton JW, Tetreault LA, Dettori JR, et al. Type and Timing of Rehabilitation Following Acute and Subacute Spinal Cord Injury: A Systematic Review. Global Spine J. 2017;7(3S):175S-194S.

10. Kirshblum S, Waring W. Updates for the International Standards for Neurological Classification of Spinal Cord Injury. Phys Med Rehabil Clin N Am. 2014 Aug;25(3):505-517.

11. Truchon C, Fallah N, Santos A, Vachon JI, Noonan VK, Cheng CL. Impact of Therapy on Recovery during Rehabilitation in Patients with Traumatic Spinal Cord Injury. J Neurotrauma. 2017;34:2901-2909.

12. Frasuńska J, Wojdasiewicz P, Tederko P, Wasiak K, Tarnacka B. Adherence to prescriptions of therapeutic exercises in patients with traumatic spinal cord injury. Ann Agric Environ Med. 2020. Online first, doi:10.26444/aaem/119941.

13. Jacobs SR, Yeaney NK, Herbison GJ, Ditunno JF Jr. Future ambulation prognosis as predicted by somatosensory evoked potentials in motor complete and incomplete quadriplegia. Arch Phys Med Rehabil. 1995;76:635-641.

14. Curt A, Keck ME, Dietz V. Functional outcome following spinal cord injury: significance of motor-evoked potentials and ASIA scores. Arch Phys Med Rehabil. 1998;79:81-86. 
15. Curt A, Dietz V. Electrophysiological recordings in patients with spinal cord injury: significance for predicting outcome. Spinal Cord. 1999;37:157-165.

16. Ellaway PH, Kuppuswamy A, Balasubramaniam AV, Maksimovic R, Gall A, Craggs MD, et al. Development of quantitative and sensitive assessments of physiological and functional outcome during recovery from spinal cord injury: A Clinical Initiative. Brain Res Bull. 2011;84:343-357.

17. Evans N, Wingo B, Sasso E, Hicks A, Gorgey AS, Harness E. Exercise Recommendations and Considerations for Persons With Spinal Cord Injury. Arch Phys Med Rehabil. 2015;96(9):1749-1750.

18. Lisiński P, Huber J. Evolution of Muscles Dysfunction From Myofascial Pain Syndrome Through Cervical Disc-Root Conflict to Degenerative Spine Disease. Spine. 2017;42(3):151-159.

19. Huber J, Lisiński P. Early results of supervised versus unsupervised rehabilitation of patients with cervical pain. Int J Artif Org. 2019;42(12):695-703,

20. Lisiński P, Huber J, Ciesielska J, Lipiec J, Kulczyk A, Bandosz A, et al. A new concept for evaluating muscle function in the lower extremities in cases of low back pain syndrome in anamnesis. Ann Agric Environ Med. 2014;21(2):375-381.

21. Tabakow P, Jarmundowicz W, Czapiga B, Fortuna W, Międzybrodzki R, Czyż M, et al. Transplantation of autologous olfactory ensheathing cells in complete human spinal injury. Cell Transplant. 2013;22(9):1591-1612.

22. Tabakow P, Raisman G, Fortuna W, Czyż M, Huber J, Li D, et al. Functional regeneration of supraspinal connections in a patient with transected spinal cord following transplantation of bulbar olfactory ensheathing cells with peripheral nerve bridging. Cell Transplant. 2014;23(12):1631-1655.

23. Leszczyńska K, Wincek A, Fortuna W, Huber J, Łukaszek J, Okurowski $S$, et al. Treatment of patients with cervical and upper thoracic incomplete spinal cord injury using repetitive transcranial magnetic stimulation. Int J Artif Org. 2020;43(5):323-331.

24. Wojtysiak M, Huber J, Wiertel-Krawczuk A, Szymankiewicz-Szukała A, Moskal J, Janicki J. Preand postoperative evaluation of patients with lumbosacral disc herniation by neurophysiological and clinical evaluation. Spine. 2014;39(21):1792-1800.

25. Jo HJ, Richardson MS, Oudega M, Perez M. The Potential of Corticospinal-Motoneuronal Plasticity for Recovery after Spinal Cord Injury. Curr Phys Med Rehabil. 2020;8:293-298.

26. Leszczyńska K, Huber J. Treatment of patients after spinal cord injuries using transcranial magnetic stimulation rTMS. Issue Rehabil. Orthop. Neurophysiol. Sport Promot. 2019;28:15-22.

27. Rossignol S, Barriere G, Frigon A, Barthelemy D, Bouyer L, Provencher J, et al. Plasticity of locomotor sensorimotor interactions after peripheral and/or spinal lesions. Brain Res Rev. 2008;57:228-240.

28. Lee BA, Leiby BE, Marino RJ. Neurological and functional recovery after thoracic spinal cord injury. J Spinal Cord Med. 2016;39(1):67-76.

29. Sandrow-Feinberg HR, Houlé JD. Exercise after Spinal Cord Injury as an Agent for Neuroprotection, Regeneration and Rehabilitation. Brain Res. 2015;1619:12-21.

30. Taylor-Schroeder S, LaBarbera J, McDowell S, Zanca JM, Natale A, Mumma S, et al. Physical therapy treatment time during inpatient spinal cord injury rehabilitation. J Spinal Cord Med. 2011;34(2):149-161.

31. Effing TW, van Meeteren NL, van Asbeck FW, Prevo AJ. Body weightsupported treadmill training in chronic incomplete spinal cord injury: a pilot study evaluating functional health status and quality of life. Spinal Cord. 2006;44(5):287-296.

32. Kirshblum S. New Rehabilitation Interventions In Spinal Cord Injury. J Spinal Cord Med. 2004;27(4):342-350. 